
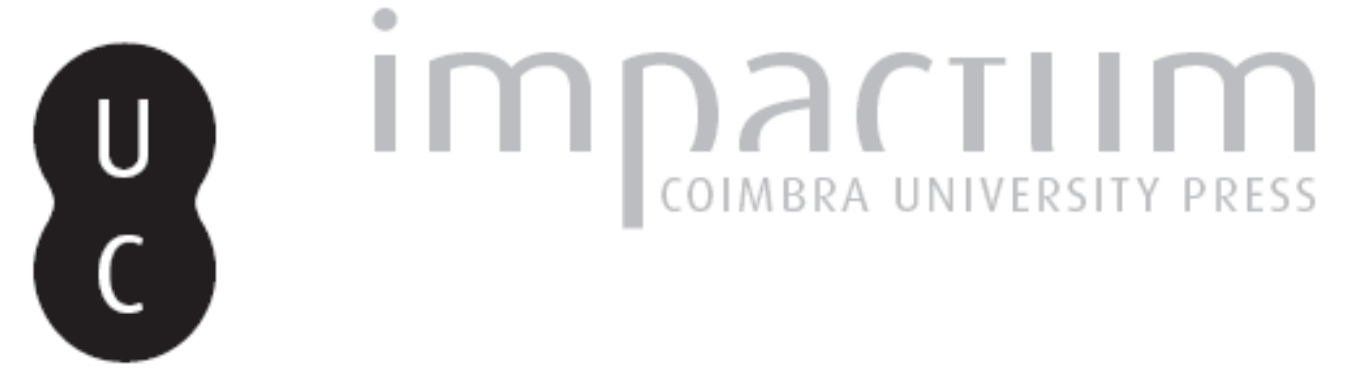

\title{
[Recensão a] PO.EX em EXPO (ou POesia EXperimental em EXPOsição): Ernesto Melo e Castro, António Barros e Silvestre Pestana na Casa da Escrita
}

\author{
Autor(es): $\quad$ Athayde, Manaíra Aires \\ Publicado por: Centro de Literatura Portuguesa \\ URL \\ persistente: \\ URl:http://hdl.handle.net/10316.2/29995 \\ DOI: \\ DOI:http://dx.doi.org/10.14195/2182-8830_1-1_10
}

Accessed : $\quad$ 26-Apr-2023 10:24:54

A navegação consulta e descarregamento dos títulos inseridos nas Bibliotecas Digitais UC Digitalis, UC Pombalina e UC Impactum, pressupõem a aceitação plena e sem reservas dos Termos e Condições de Uso destas Bibliotecas Digitais, disponíveis em https://digitalis.uc.pt/pt-pt/termos.

Conforme exposto nos referidos Termos e Condições de Uso, o descarregamento de títulos de acesso restrito requer uma licença válida de autorização devendo o utilizador aceder ao(s) documento(s) a partir de um endereço de IP da instituição detentora da supramencionada licença.

Ao utilizador é apenas permitido o descarregamento para uso pessoal, pelo que o emprego do(s) título(s) descarregado(s) para outro fim, designadamente comercial, carece de autorização do respetivo autor ou editor da obra.

Na medida em que todas as obras da UC Digitalis se encontram protegidas pelo Código do Direito de Autor e Direitos Conexos e demais legislação aplicável, toda a cópia, parcial ou total, deste documento, nos casos em que é legalmente admitida, deverá conter ou fazer-se acompanhar por este aviso.

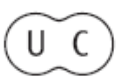




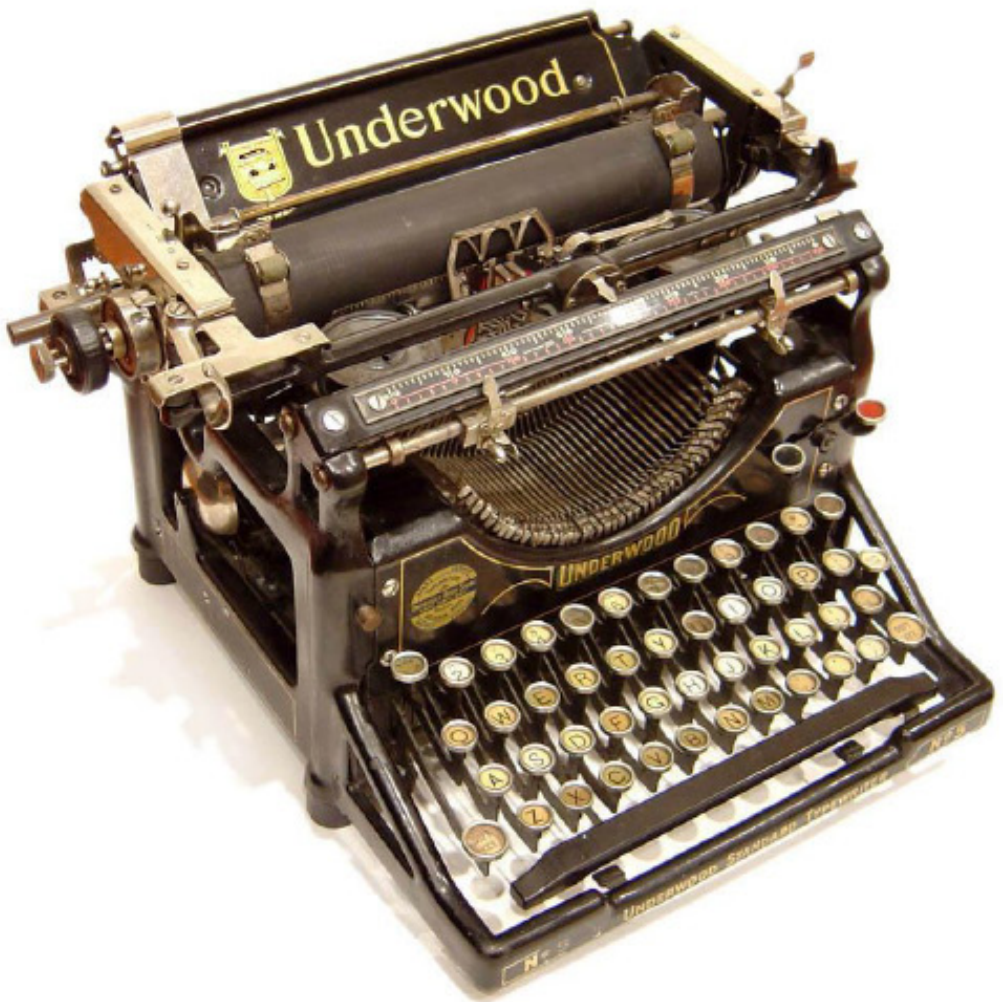

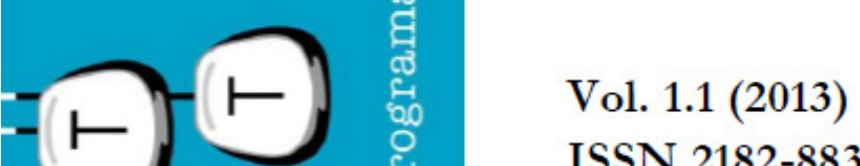

ISSN 2182-8830

'Estranhar Pessoa com

as Materialidades da Literatura'

Orgs. Manuel Portela \&

Osvaldo Manuel Silvestre 


\author{
PO.EX em EXPO \\ (ou POesia EXperimental em EXPOsição): \\ Ernesto Melo e Castro, António Barros \\ e Silvestre Pestana na Casa da Escrita \\ MANAÍRA AIRES ATHAYDE \\ Universidade de Coimbra \\ Bolseira da CAPES
}

Ernesto MELO E CASTRO, Do Leve à Lur, de 03 de outubro a 02 de novembro de 2012. António BARROS, Progestos_Obgestos, de 30 de novembro a 21 de dezembro de 2012. Silvestre PESTANA, Povo Novo Virtual, de 08 de fevereiro a 01 de março de 2013. Ciclo NAS ESCRITAS PO.EX, Casa da Escrita, Coimbra, Portugal.

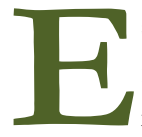

spumas flutuantes, cordas alinhavadas a espelhos côncavos, folhas de alumínio suspensas, poética de molduras e ecrãs, leds e néons em puzzlle. Este é o "play time" que a Casa da Escrita, em Coimbra, recebe de outubro de 2012 a junho de 2013, com retrospectivas de grandes nomes da Poesia e da Arte Experimental Portuguesa. O ciclo, batizado de «Nas Escritas PO.EX» e comissariado por Jorge Pais de Sousa em parceria com o projeto «PO.EX'70-80: Arquivo Digital da Literatura Experimental Portuguesa», exibe exposições individuais de Ernesto Melo e Castro, António Barros, Silvestre Pestana, Fernando Aguiar, Manuel Portela e Ana Hatherly (no plano original, havia ainda a exposição de Alberto Pimenta, em janeiro de 2013, e de Jorge Lima Barreto, em março de 2013; aquela acabou por não acontecer e esta transformou-se numa jornada dedicada à obra musical e musicológica do artista, falecido a 9 de julho de 2011, pouco depois de ser convidado para participar do ciclo). Nesta recensão, centraremo-nos nas três primeiras exposições realizadas num primeiro momento, de outubro de 2012 a fevereiro de 2013, com a perspectiva de apresentar na próxima edição da Revista MatLit uma segunda recensão assinalando as outras três que encerram o ciclo.

$\mathrm{Na}$ primeira exposição, «Do Leve à Luz», patente entre 03 de outubro e 02 de novembro de 2012, deparamo-nos com uma retrospectiva que funciona como síntese de todo o intervencionismo experimental, cujas estirpes vão sendo exploradas nas exposições subsequentes através das singularidades do trabalho de cada artista convidado. É que estamos a falar de um artista que tem grande capacidade de abrangência e transversalidade, 
um dos nomes mais interventivos do experimentalismo português e um dos seus primeiros entusiastas, não só no âmbito da criação poética, mas como um dos seus primeiros teorizadores. Um artista de palavras compostas tecnopeia, infopoesia, videopoema - e de muitos advérbios, adjetivos superlativos, onomatopeias.

Ernesto Melo e Castro. No alto dos seus 80 anos completados na altura da exposição, há muito usa uma barba à Marx e não tem idade que refreie a sua engenhosa mente high-tech. Cirurgião da palavra, ou melhor, cirurgião plástico da palavra, é o exemplo vivo do artista-investigador, aquele que faz do ateliê um laboratório e que busca não apenas o que está além da obra, mas o que está diante dela. A precisão ou a nitidez de campo é abjurada em nome da diluição de fronteiras, onde não se teme incorporar o que está fora de foco, fora de controle. O enquadramento passa a interessar não mais pelo que está dentro da tela - do painel, do ecrã -, e sim pelo que é extrínseco a ela. A escolha é movida, por vezes, pelo que não se quer enquadrado.

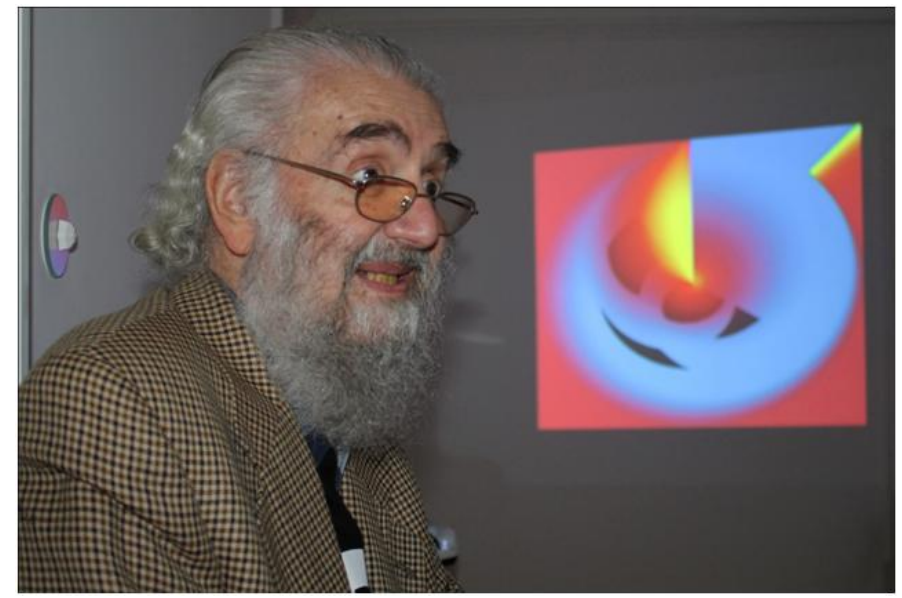

Ernesto Melo e Castro e o seu videopoema «Imagens sem Fim». «Eu sei que estou aproximando-me perigosamente do fim. Por isso é que naquelas imagens que você tem ali há "imagens sem fim". Negar o fim porque tudo continua doutra maneira», afirma em entrevista.

E filho pródigo destas entalpias, engenheiro têxtil que é, formado em Inglaterra em 1956, Melo e Castro incorpora o espírito do século XX: o artista como um verdadeiro pesquisador-inventor que vai dosando sua química até obter o elixir criativo. Para isso é necessário olhar com acuidade para a matéria, limando-a, descamando-a, amalgamando-a. $\mathrm{O}$ suporte passa a ser o elemento-chave da sintaxe, determinante na semiose e no crescimento dialético contínuo, em que a obra pende para o caráter aberto e dinâmico.

A noção de obra pura, de pureza do signo genuíno é abandonada. Em seu lugar são reverberadas as concepções de montagem e colagem, em que elementos de naturezas distintas (objetos reais, objetos virtuais, linguagem 
verbal, linguagem iconográfica) se encontram numa mesma composição e modificam por completo a noção de objeto de arte, agora híbrido, ao tempo em que as linguagens verbal e visual estabelecem relações cada vez mais contíguas e acentuam o poder da metalinguagem. Aguça-se a apropriação e a reprodução de elementos, e a arte não tem por intuito ou dever questioná-las.

Resultado? Os efeitos sensoriais e sinestésicos e os estranhamentos, que surgem como céleres respostas aos novos procedimentos composicionais e que passam a alterar a idiossincrasia coletiva. A Arte Contemporânea, não obstante, é talvez uma entrópica resposta à complexidade crescente do mundo, visando à desconstrução dos aspectos semânticos que representam a realidade com a qual a sociedade tradicionalmente - e idealmente - identificase. Tanto é que o nosso artista, como muitos outros, várias vezes se viu confrontado com o "ah, isto o meu filho ou o meu cão era capaz de fazer", como revela em entrevista (disponível em «Ernesto Melo e Castro e a sua máquina do tempo»). A quebra da representação tradicional é também o rompimento com a linearidade, numa modificação fulcral do pensamento, que passa a ser multilinear e rizomático.

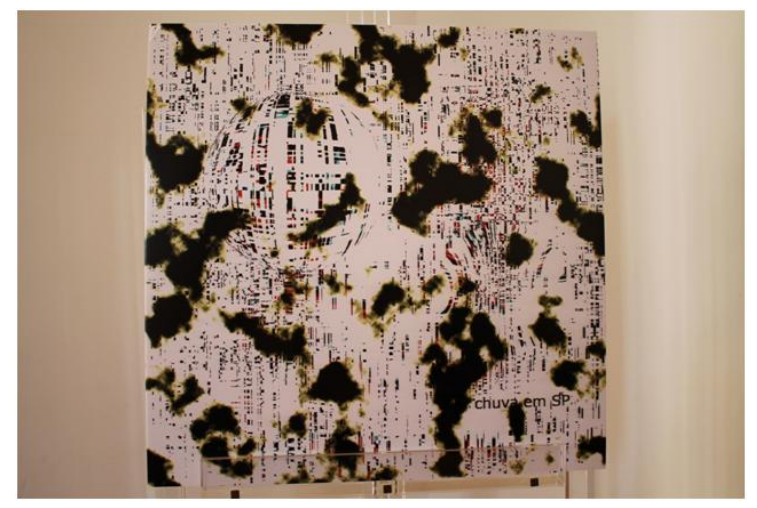

«Chuva em São Paulo».

Assim, o trabalho de artistas como Ernesto Melo e Castro acaba por ser a representação visual para conceitos abstratos, a partir da radicalização da experiência com a matéria. Não é à toa que a linguagem oriental do ideograma, por exemplo, torna-se uma grande fonte de pesquisa - inclusive, Melo e Castro publica o livro «Ideograma» em 1961, quando então traz para Portugal a Poesia Concreta, irrupcionada no Brasil anos antes, e se torna precursor do experimentalismo na poesia lusitana.

Hoje, o escritor português, radicado no Brasil, onde se doutora em Letras pela USP em 1998 e conclui o pós-doutorado na UFMG em 2011, deixa-nos um abastado acervo de objetos e de memórias, importante para a compreensão da arte experimental em Portugal, "ausente do stream da Arte Contemporânea Portuguesa”, como aponta Pedro Reis, um dos curadores da exposição. Na abertura da mostra, a 03 de outubro de 2012, Pedro Reis ainda 
menciona o pioneiro videopoema «Roda Lume», feito por Melo e Castro em 1968 e exibido pela RTP no ano seguinte, para sublinhar os litígios com a Poesia Experimental. "Nós, portugueses, não conseguimos mostrar lá fora nem estudar as consequências que este primeiro videopoema teve no mundo da Arte Contemporânea", afirma o professor.

A Poesia Experimental, que parece algures lutar contra a sua forte marcação histórica, tenta não ser engolida pelo «TecnoCronos», com a banalização das práticas experimentais-tecnológicas. "Hoje já não é mais uma técnica transcendente, eu tenho consciência disso", diz Melo e Castro diante de um dos seus videopoemas. Mais do que uma autogeração, no passado, trata-se agora de uma autorregeneração desta poesia empírica, fruto de um deus que se sabe, mais cedo ou mais tarde, devorar seus filhos.

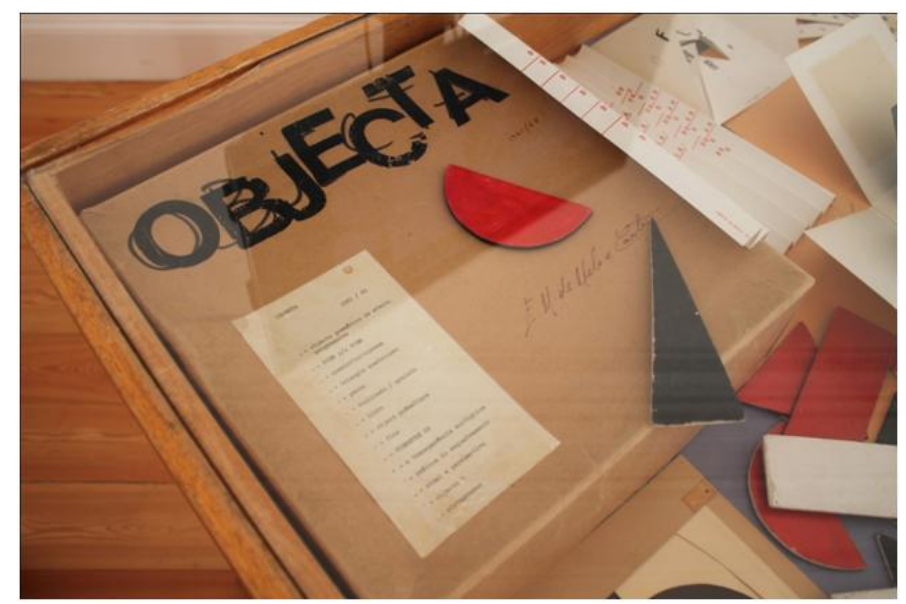

Detalhe da obra «Objecta (conteúdo)», com suas peças «mobiles» realizadas nos anos 50 e 60 . O trabalho pertence à coleção do Museu de Serralves.

Aliás, ao percorrer as salas onde decorre «Do Leve à Luz» - que conta, dentre outros, com 14 obras inéditas de infopoesias, realizadas depois da grande retrospetiva dedicada a Melo e Castro no Museu de Serralves, em 2006 -, é possível perceber um ambiente expositivo firmado como um nãolugar, um sítio de sensação e passagem. Os trabalhos de toda uma vida podem ser impressos em papel comum, expostos em cartolinas, dessacralizados da moldura, do pedestal; elementos intercambiáveis em práticas artísticas que não os implanta, mas os distribui e os faz circular numa rede de relações, num cruzamento de mobiles que coloca em questão as nuances entre reprodução e apropriação, abstração e matéria, espaço e tecnologia.

Se essa matiz em Ernesto Melo e Castro se quer cada vez mais intercambiável, em «Progestos_Obgestos» o itinerário de António Barros é um convite às intermitências (e às suas fissuras fixas): a casa como o espaço 
que existe entre o branco e o preto, o intervalo entre o que se diz e o que se entende, o interstício entre o rebuscado léxico e as límpidas obras. Afinal, é na fenda às fechaduras que as instalações de António Barros acontecem.

$\mathrm{Na}$ exposição, de 30 de novembro a 21 de dezembro de 2012, o artista estabelece diálogo entre as obras e as divisões da Casa da Escrita, acomodando as instalações, por vezes, no mobiliário da casa. Objetos brancos e negros criam uma propulsão dual, numa espécie de jogo mnemônico, onde uma casa imaginária é criada a partir de lugares familiares e os seus suscitados estranhamentos. Os resquícios de memória sobrevivem da coisificação das relações espaciais.

Caminhar pela grande «casa a preto e branco» de António Barros é como atravessar alguns fulcros da filosofia de Theodor Adorno: a busca do negativo do real para entender a realidade, numa dialética iluminista que procura a emancipação da dissonância. Barros, com sua epifania clean, deixa claro ser um «artista da razão». O fim do pensamento crítico nos dias que correm é, para o artista, o devir de uma idade das trevas. «A poesia experimental, hoje, é uma poesia pretensamente organicizante, que busca a raiz da sua condição enquanto motor e afirmação do ser, que diz na sua natureza fundamental. Tudo como quem zela por desenhar numa narrativa propulsora, esta do ser que se questiona perante o chegar de uma nova Idade Média a querer insinuar-se», alega em entrevista (disponível em «No itinerário de António Barros»).

«Razão / Muro da Razão» é uma das instalações que fulguram este declínio da razão e a crise da representação. $\mathrm{Na}$ obra, sacos brancos, em forma de travesseiros e com a parte superior a enunciar a palavra «RAZÃO», são empilhados em fileiras num louceiro embutido na parede. As fileiras diminuem da esquerda para a direita, como se num gráfico de colunas em que a «RAZÃO»é a unidade que míngua.

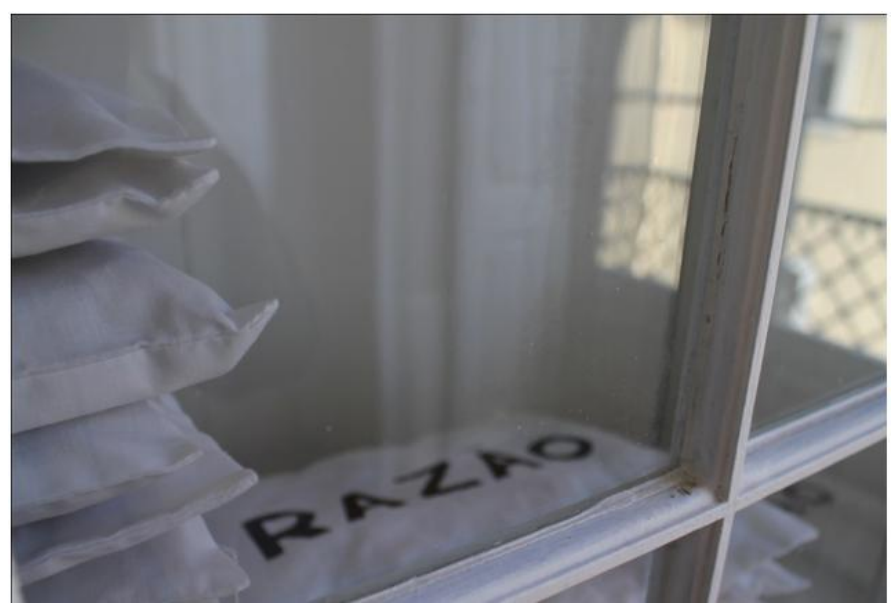

Detalhe de «Razão / Muro da Razão». 
Da experimentação à experienciação, a poesia experimental é, afinal, para o artista uma grande égide do pensamento crítico-reflexivo. Esta disposição levou-o a integrar o grupo Movimento Fluxus, que desde os anos 1960 fomenta as interartes e defende a negação do objeto artístico tradicional como mercadoria, divulgando a «antiarte». António Barros e seus companheiros, tais como Wolf Vostell, Robert Filliou e Serge III Oldenbourg, levaram a matéria ao extremo, abrangendo-a em todas as suas possibilidades para, por revés, fazer sobressair o arcabouço conceitual, ideológico.

Para António Barros, o que existe de mais peculiar no experimentalismo da arte contemporânea é a «capacidade de ser poesia, condição para dizer o ser e a sua circunstância numa transversalidade multímodo e plural sem precedentes, que justifica o gesto», comenta. Uma conduta pró-gesto, uma conduta pro (para o) gesto que domestica cômodos com o rigor de um artista que se encena narrador-observador na teatralização de imagens, como na performance do homem invisível. Nela, um casaco negro é acomodado numa cadeira como se estivesse numa pessoa sentada diante de uma máquina de escrever. Instrumento diante de outro instrumento, dígito ao lado de dígito que mão escreve o transcurso maquinal?

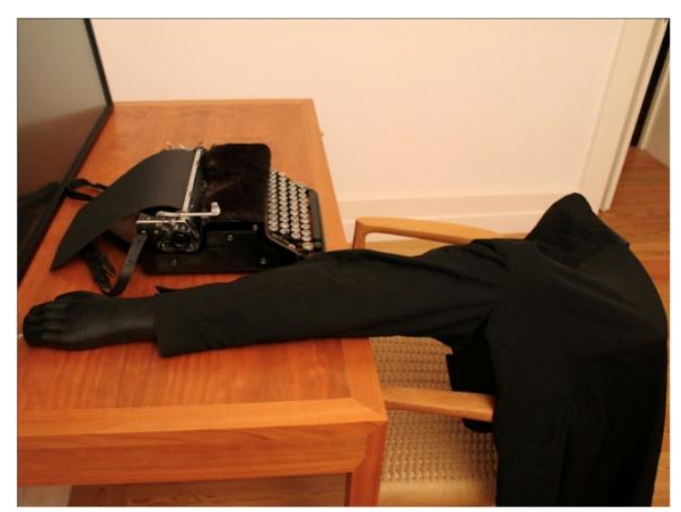

«Vulto Limite».

Num mundo pós, António Barros é um artista pró, que vê nos seus gestos taxonômicos um exercício em busca da luz/cidez. Em sua obra, a ordem é desordenar em ordem, numa organização da entropia que culmina em concepções herméticas, mas aplicadas a trabalhos dotados de simetria e limpeza na profusão de luz - para a resistência das luzes nesta época quase Idade Média, como defende o artista, por suas propulsões acríticas.

Aliás, numa altura em que a arte experimental, com toda a sua capacidade de reprodução e apropriação, sofre um grande desvio de seu cerne quando é utilizada por muitos artistas para sombrear a incapacidade técnica e a indisponibilidade material, António Barros surge com uma boa disposição ideológica, embora ela não garanta a singularidade do negativo. 
Ainda que o artista tenha a acuidade necessária para que o efeito estético não se torne adorno da ideologia e para que não seja o conteúdo a ditar a estrutura, saímos da exposição com vontade de mais. Quiçá de um António Barros que crie estruturas taxonômicas dentro de um mundo caótico, e não que apenas tente organizá-lo. Aqui se estende o desafio. Afinal, viver (n)um mundo a cores pode ser mais difícil do que parece.

Por outro lado, um mundo a cores (e de vibrantes cores) é o que não falta na exposição «Povo Novo Virtual», de Silvestre Pestana, que se aproxima de Ernesto Melo e Castro na busca pela palavra e pela sonoridade, e de António Barros pelas matizes da performance. Na exposição, patente de 8 de fevereiro a 01 de março de 2013 , vemos as palavras

$\begin{array}{ll}\text { Ovo------------TERRA } \\ \text { mar } & \text { SER } \\ \text { fenda } & \text { SUOR } \\ \text { ar } & \text { ILHA } \\ \text { ego } & \text { POVO } \\ \text { medo } & \text { TER } \\ \text { fogo } & \text { HOMEM } \\ \text { asa } & \text { ERVA }\end{array}$

distribuídas numa espécie de circuito com botões coloridos, eletrificados e intermitentes no chão, que dialogam com quatro grandes fotografias de 1979, dentre elas a famosa «Povo Novo», uma das obras mais representativas do pós 25 de Abril. Não há oscilações cinéticas nas luzes, mas a imersão na obra exige que o fruidor a complete com movimento, imaginando-o não só pelo perímetro iluminado mas em razão do vidro estilhaçado que três das imagens focam. É esse «Tecno-labirinto» que nos apresenta o espaço onde o presente reabilita o passado desse novo povo novo de que Silvestre Pestana nos fala, numa exposição que comemora os 45 anos de carreira do artista madeirense, que migrou para o Porto em fins da década de 60 e que nos últimos cinco anos do regime salazarista esteve exilado na Suécia.

Aliás, em Silvestre Pestana os caminhos são sempre uma espécie de bypass que reflete a síntese do trabalho desenvolvido sobre o invólucro de um mundo digital: tanto quanto de orgânico possamos encontrar em código maquinal quanto de analógico há no próprio dígito. É isto: o orgânico revestido pelo programado e o labirinto simplificado em circuito. Pois, o artista herda das ciências o rigor do método e nos conduz, sobre um eixo que acompanha toda a sua produção artística, a questionamentos inscritos por múltiplos recursos em distintos meios, numa perspicaz exploração das propriedades materiais. São diferentes trajetos que acabam por desaguar no mesmo rio, atingido por vários fluxos com sentidos díspares, mas direções convergentes intersecionadas pelas conjeturas do artista. 


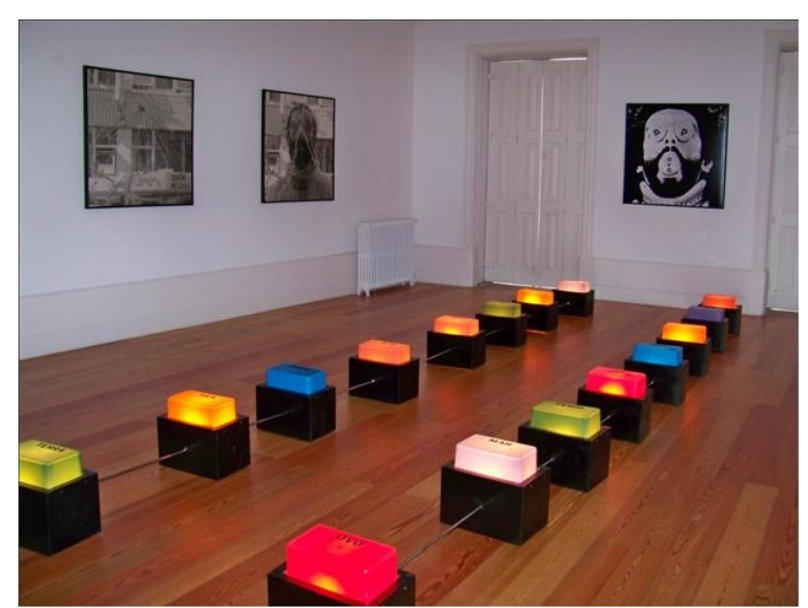

Visão parcial de «Tecno-labirinto» (1979), instalação composta por quatro fotografias de $100 \times 100 \mathrm{~cm}$ e por 16 peças eletrificadas. A fotografia que não aparece na imagem é a reprodução da última fotografia da parede esquerda e está posicionada simetricamente a ela na mesma parede.

Eis nesses questionamentos o que o artista chama de «problema das constantes entre-coisas». No trabalho de Silvestre Pestana, podemos observar que há uma (dis)tensão entre a potência - as possibilidades do ser, aquilo que ainda não é mas pode vir a ser - e o ato, a ação - a manifestação atual do ser, aquilo que já existe -, numa discussão ontológica que é maquinada sob uma perspetiva sociologizada. (Até a transição que o artista faz para o mundo virtual vem intensificar a problemática da potência em sua obra, afinal, a palavra «virtual» está originalmente ligada à ideia de «vir a ser»). Daí ser tão caro ao artista elementos como o útero, a estufa, o aquário e, claro, o ovo.

O ovo, aliás, mais do que morfema, aparece como ideia incisiva da obra de Silvestre Pestana no núcleo da problemática da potência aristotélica: a fecundação do ser múltiplo é condicionada pelo dispositivo, que permite ou não a sobrevivência. Por isso a associação do ovo ao «povo novo», quer aquele que depois do 25 de Abril, quer aquele que hoje imerso num mundo cada vez mais high tech. «O povo com a potencialidade de novos caminhos inscritos na arte da liberdade, de ser na própria existência», explica o artista em entrevista («Do início, do(s) meio(s) e do fim em Silvestre Pestana»).

Silvestre Pestana se move das artes abstratas às poéticas da performatividade, da tradição radicalizada no concretismo brasileiro ao grafismo pós-revolucionário russo dos anos 20. «Tudo para fazer versões de como um povo se expressa nas suas singularidades», explica o artista da «poética sociológica», inscrita ao longo de toda a sua trajetória, do poemaprocesso ao poema-avatar. 


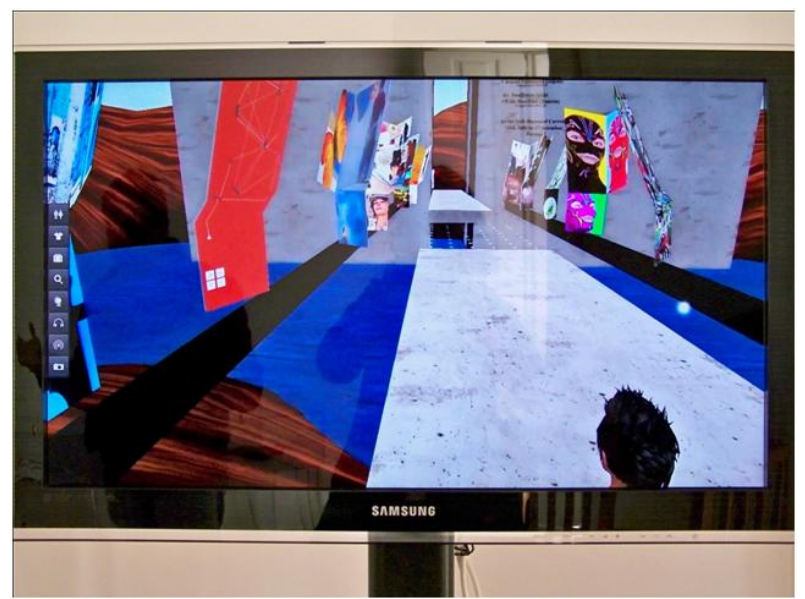

«Avatar» (2012), em que Silvestre Pestana e Vitus Flores utilizam o Second Life para criar no mundo virtual a $6^{\mathrm{a}}$ Bienal Internacional de Gravura do Douro.

Através do «poema catatónico» - que «diz que um ato é gerador de uma poética, e isto o concretismo não havia feito», ressalva -, Silvestre Pestana conseguiu encontrar na performance um percurso cada vez mais singular. Dono de uma selvagem delicadeza ou, se quisermos, de uma rebeldia "artistizada", de pujante posição ideológica e ativismo social - «Aprendi aos 16 anos uma premissa de Paulo Freire que me acompanha até hoje: "o bom artista faz anúncio e depois faz denúncia"» -, nas molduras socioculturais conseguiu encontrar novas fronteiras: falar sem limítrofes sobre o homem e a natureza, o homem e a guerra, o homem e o planeta.

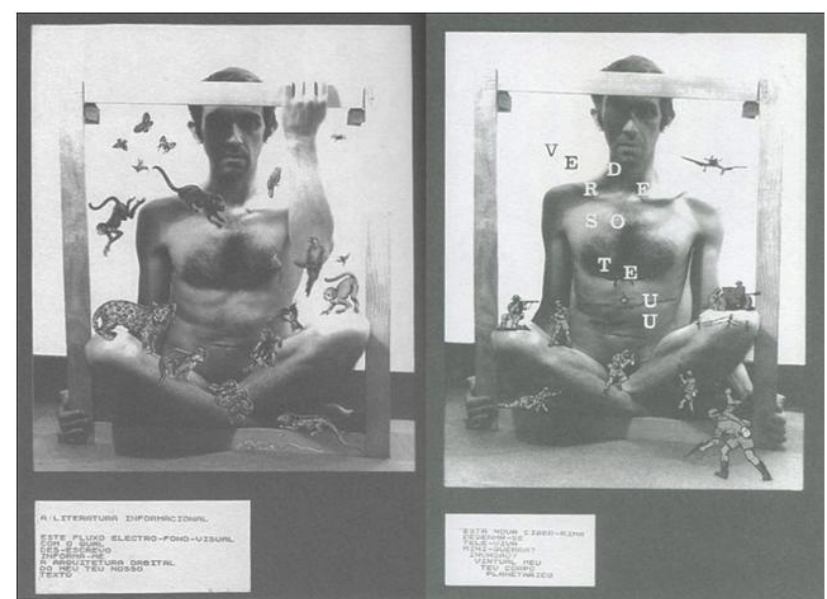

Trabalhos, sem títulos, de 1985. Silvestre Pestana segura uma moldura de madeira, tematizada de maneira diferente a cada performance. 
Aliás, em Silvestre Pestana vamos encontrar uma poética de molduras e ecrãs, de leds e néons. Polígonos de silhuetas luminosas, como em «Meteoro Néon para Vénus» (2001), ou rizomas fluorescentes em seus «Fractais» (2002). Fulgência do espaço numa sociedade meteórica, numa sociedade rizomática. Obras, não obstante, compostas por sistemas a-centrados, em que o privilégio é dos meios, dos intervalos, numa rede de autómatos finitos. Não há um decalque, uma cópia de uma ordem central, mas conexões estabelecidas entre todos os caminhos possíveis para a mesma problemática. «Criar os meios para poder percorrer os fins», diz o artista.

Essas conexões, porém, mais do que construir um «intencional hibridismo de linguagens» ou uma «contaminação signíca» (Sousa \& Ribeiro, Antologia da Poesia Experimental Portuguesa, 2004, p. 353), chamam a atenção na obra de Silvestre Pestana porque, enquanto facultam a experiência do meio, cada um dos elementos está no outro e no outro cria o seu próprio espaço, sem, no entanto, fundir-se para resultar em hibridações. Por isso, trata-se de uma poética sociológica em sua destreza rizomática, pois os elementos não se fundem para formar um terceiro, mas são em si o percurso que há também nos outros. Uma obra de estrutura rizomática que, longe de ser fundamentalmente inflexível, define territórios estáveis dentro dos rizomas.

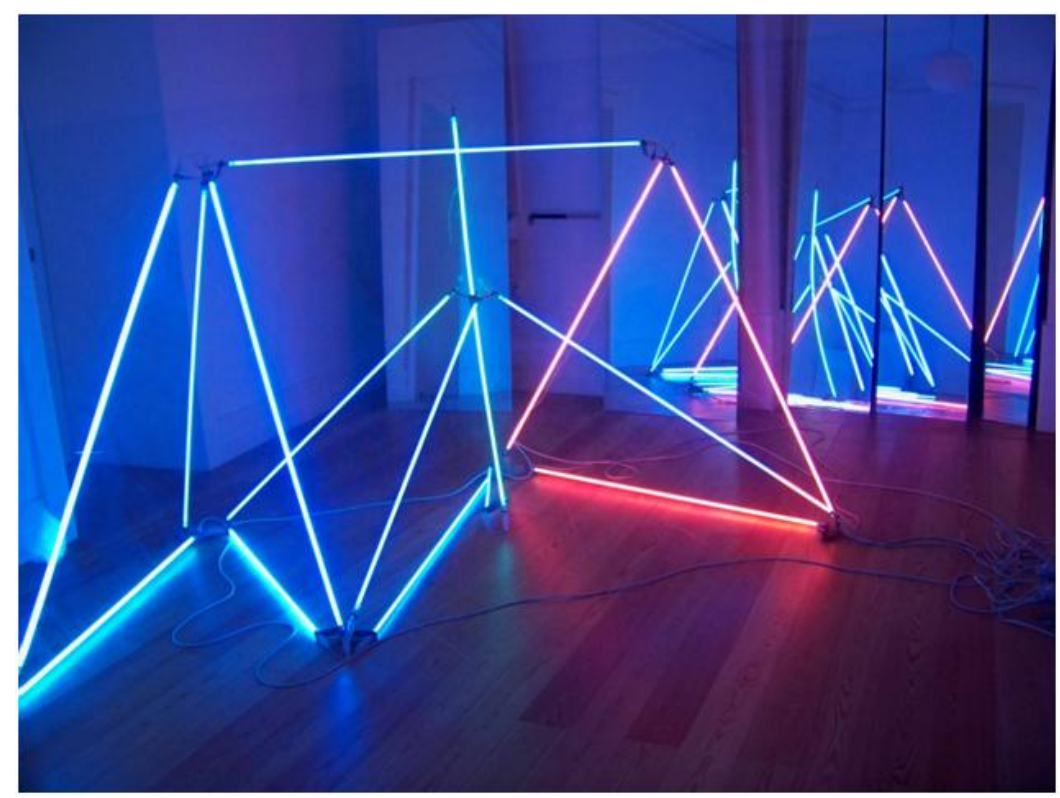

«Meteoro Néon para Vénus» (2001), instalação em néon com dimensões de 260 x 180 $\mathrm{x} 120 \mathrm{~cm}$. 


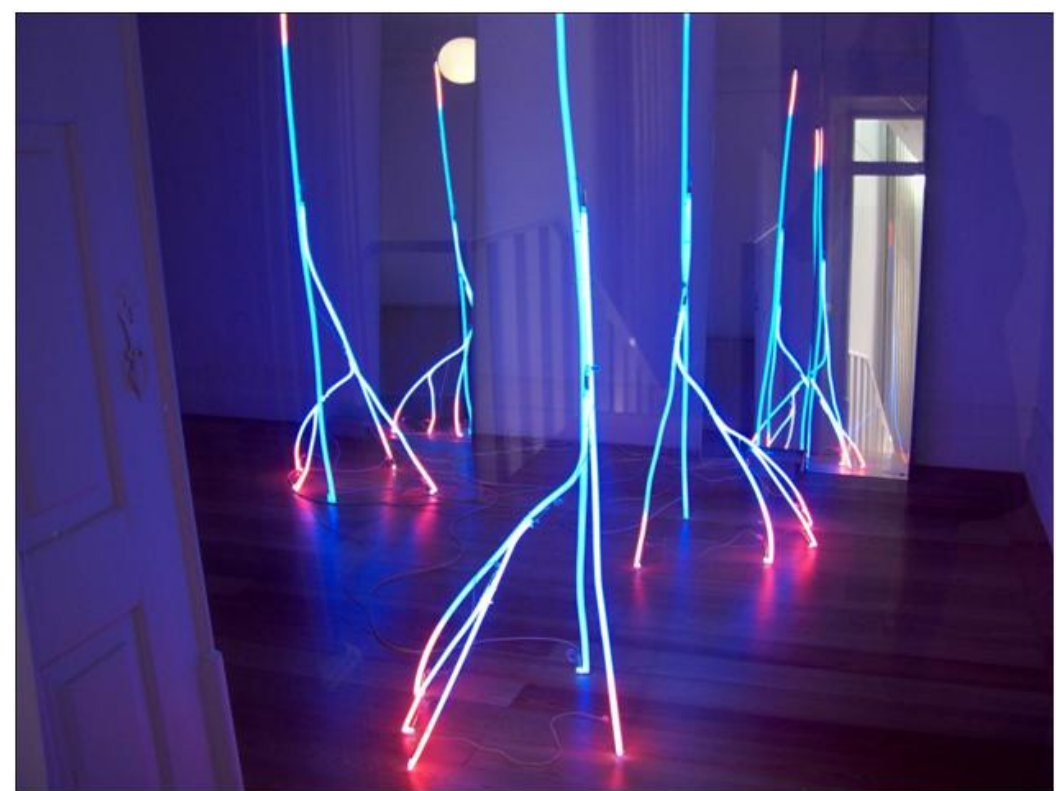

«Fractais» (2002), instalação em néon com dimensões de 190 x 80 x 80 cm.

Pois de raízes intercambiáveis, quando não incandescentes, Silvestre Pestana é esse artista-mundo que, com toda a paixão e compromisso que tem para com tudo o que fez e continua a fazer, instiga a refletirmos sobre as gerações e os seus meios de inscrição. $\mathrm{O}$ universo de Pestana é uma boa oportunidade para entendermos os «grãos de simplicidade», como ele costuma dizer, da coexistência (existência-potência, existência-ato) entre o passado e o presente nessa crise dos tempos, ou tempos de crise.

Aliás, não só o universo de Silvestre Pestana, mas o de Ernesto Melo e Castro e o de António Barros permitem-nos atualizar este presente tão amplo pelo acúmulo diferentes mundos passados, numa esfera de simultaneidade que substitui a temporalidade por um novo espaço, não mais definido pela linearidade de relações causais ou sequenciais, mas firmado por relações simultâneas que preterem a posição teleológica pela contingência de mundo. Um tempo plurilinear, que longe de ser a sucessão de períodos, regista-se como um presente que, fixo em si enquanto se move adiante, é atingido por várias linhas de eventos com sentidos e direções diferentes. Um tempo, um espaço que nesses artistas, com suas poéticas experimentais à $\mathrm{XX}$, não poderiam ser mais do que nossos, neste início de século.

(C) 2013 Manaíra Aires Athayde. (C) 2013 Fotos de Manaíra Aires Athayde. 